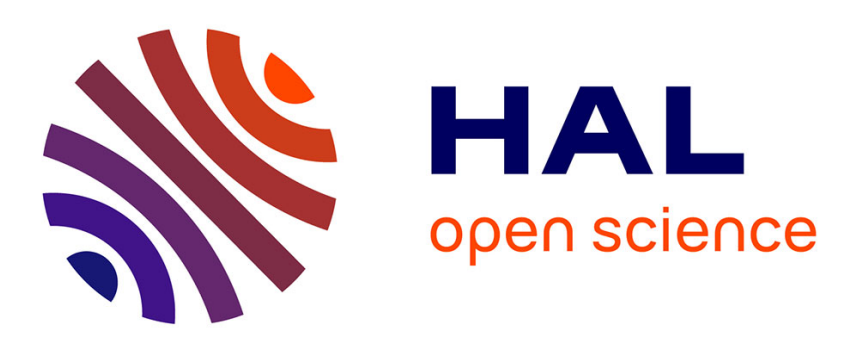

\title{
Nonlinearity of bituminous materials for small amplitude cyclic loadings
}

Quang Tuan Nguyen, Mai Lan Nguyen, Hervé Di Benedetto, Cédric Sauzeat, Emmanuel Chailleux, Thi Thanh Nhan Hoang

\section{- To cite this version:}

Quang Tuan Nguyen, Mai Lan Nguyen, Hervé Di Benedetto, Cédric Sauzeat, Emmanuel Chailleux, et al.. Nonlinearity of bituminous materials for small amplitude cyclic loadings. Road Materials and Pavement Design, 2018, 26p. 10.1080/14680629.2018.1465452 . hal-01916421

\section{HAL Id: hal-01916421 https://hal.science/hal-01916421}

Submitted on 8 Nov 2018

HAL is a multi-disciplinary open access archive for the deposit and dissemination of scientific research documents, whether they are published or not. The documents may come from teaching and research institutions in France or abroad, or from public or private research centers.
L'archive ouverte pluridisciplinaire HAL, est destinée au dépôt et à la diffusion de documents scientifiques de niveau recherche, publiés ou non, émanant des établissements d'enseignement et de recherche français ou étrangers, des laboratoires publics ou privés. 
Nonlinearity of bituminous materials for small amplitude cyclic loadings

Quang Tuan Nguyen ${ }^{\mathrm{a}^{*}}$, Mai Lan Nguyen ${ }^{\mathrm{b}}$, Hervé Di Benedetto ${ }^{\mathrm{c}}$, Cédric Sauzéat $^{\mathrm{c}}$, Emmanuel Chailleux ${ }^{\mathrm{b}}$, Thi Thanh Nhan Hoang ${ }^{\mathrm{a}}$

${ }^{a}$ University of Transport and Communications, Hanoi, Vietnam

*quangtuan.nguyen@utc.edu.vn

${ }^{b}$ IFSTTAR, F-44344 Bouguenais, France

${ }^{c}$ LTDS (UMR CNRS 5513), University of Lyon /Ecole Nationale des Travaux Publics de l'Etat (ENTPE), Vaulx-en-Velin Cedex, France 


\title{
Nonlinearity of bituminous materials for small amplitude cyclic loadings
}

\author{
This paper focuses on the influence of the cyclic loading amplitudes on the \\ behaviour of bitumen and bituminous mixtures. The present work considers only \\ rather small strain amplitude (lower than $100 \mu \mathrm{m} / \mathrm{m}$ for mixtures and $10 \%$ for \\ bitumen). Complex modulus tests on mixtures were conducted at four levels of \\ strain amplitude for a large range of temperatures and frequencies. Tension - \\ compression tests at the temperatures lower than $20^{\circ} \mathrm{C}$ and shear tests at \\ temperatures higher than $20^{\circ} \mathrm{C}$ were performed to measure the complex modulus \\ of bitumen which is used to produce the mixtures. Moreover, individual strain \\ tests, strain sweep tests and fatigue tests at $10^{\circ} \mathrm{C}, 30^{\circ} \mathrm{C}$ and $50^{\circ} \mathrm{C}$ were carried out \\ to study the influence of the strain amplitude and cyclic effects on the complex \\ modulus of bitumen. The obtained results indicated that the nonlinearity (effect \\ of strain amplitude) on both bitumen and bituminous mixtures respects the Time \\ Temperature Superposition Principle (TTSP). However, the temperature - \\ frequency has inverse effects on the nonlinear behaviour of bitumen and \\ bituminous mixtures. The cyclic effect was shown to be not negligible when \\ analysing the nonlinearity phenomenon.
}

Keywords: nonlinearity, bitumen, bituminous mixtures, complex modulus

\section{Introduction}

It is widely observed that bituminous materials exhibit nonlinear behaviour which means in this paper a modulus depending on strain (or stress) amplitude. The viscoelastic linearity limits of bitumens and bituminous mixtures have been reported in many studies (Airey, Rahimzadeh, \& Collop, 2003; Airey \& Rahimzadeh, 2004; Di Benedetto, Olard, Sauzéat, \& Delaporte, 2004; Nguyen, Di Benedetto, \& Sauzéat, 2015a). These linearity limits are defined as the strain/stress amplitude corresponding to a decrease of $5 \%$ in the complex modulus and varies from about $100 \mu \mathrm{m} / \mathrm{m}$ for bituminous mixtures up to some per cent for bitumens (Airey \& Rahimzadeh, 2004). Within the viscoelastic linear (VLE) region, the Time Temperature Superposition 
Principle (TTSP) was shown to be successfully applicable to bituminous materials: bitumens (Mangiafico et al., 2013), mastic (Delaporte, Di Benedetto, Chaverot , \& Gauthier , 2009) and bituminous mixtures (Di Benedetto, Delaporte, \& Sauzéat, 2007; Nguyen, Di Benedetto, Sauzéat, \& Tapsoba, 2013; Baaj, Ech, Tapsoba, Sauzéat, \& Di Benedetto, 2013; Pham et al., 2015a; Perraton et al., 2016; Di Benedetto , Sauzéat, \& Sohm, 2009). Some authors verified the TTSP in nonlinear domain (Chehab, Kim, Schapery, Witczak, \& Bonaquist, 2002; Schwartz, Gibson, \& Schapery, 2002; Zhao \& Kim, 2003; Nguyen, Sauzéat, Di Benedetto, \& Tapsoba, 2013; Nguyen, Di Benedetto, Sauzéat, Nguyen, \& Hoang, 2017).

The decrease in measured complex modulus of bituminous materials during cyclic loadings can be the consequence of different mixed phenomena: nonlinearity, heating, fatigue, thixotropy (Di Benedetto, Nguyen, \& Sauzéat, 2011; Tapsoba, Sauzéat, \& Di Benedetto, 2013; Mangiafico et al. 2015; Babadopulos, Sauzéat, \& Di Benedetto, 2017) that makes the analysis and qualification of phenomena quite complex. In this paper, the nonlinearity phenomenon is defined as the change in complex modulus observed when changing the value of applied loading amplitude (effect of loading amplitude). The cyclic effects (that include self-heating, fatigue and thixotropy) are characterised by the decrease in modulus with the number of applied cycles. This paper focuses on the influence of the cyclic loading amplitudes (nonlinearity phenomenon) on the behaviour of bitumen and bituminous mixtures. To fulfil the research objective, complex modulus tests on bitumen and bituminous mixtures were conducted at different levels of strain amplitude. The strain amplitudes applied in these tests were controlled to be rather small, lower than $100 \mu \mathrm{m} / \mathrm{m}$ for mixtures and lower than $10 \%$ for bitumen. Some authors performed the stress/strain sweep tests to study the nonlinearity phenomenon on bitumens (Airey \& Rahimzadeh, 2004; Gauthier, Bodin, Chailleux \& 
Gallet, 2010; Underwood \& Kim, 2015; Mangiafico, Babadopulos, Sauzéat, \& Di Benedetto, 2017; SHRP-A-370) where the effects of cyclic loading and stress/strain amplitude are combined. In the present work, a test protocol on bitumen and bituminous mixtures was proposed to eliminate cyclic effects. In addition, strain sweep tests and fatigue tests on bitumen were carried out to analyse cyclic effects in comparison with nonlinearity effect. Tests on bitumen and mixtures were conducted at different temperatures and frequencies to show how these parameters affect the nonlinearity phenomenon. From the obtained results, the nonlinear behaviour from bitumen to bituminous mixtures was analysed.

\section{Materials and test equipment}

\subsection{Materials}

A 35/50 (penetration grade) pure bitumen was tested in this study. This bitumen was used to produce two mixtures, named BM1 and BM2. Two mixtures were produced by mixing the $0 / 14 \mathrm{~mm}$ aggregate with the same $4.5 \%$ bitumen content by total weight. The aggregate grading of BM1 and BM2 is continuous and gap-graded, respectively.

\subsection{Test equipment}

\section{Test equipment for bitumen}

The Metravib's DMA (Dynamic Mechanical Analyzer) press was used for the tests on bitumen. The press is equipped with a $450 \mathrm{~N}$ load cell and a $500 \mu \mathrm{m}$ displacement sensor. It allows a wide range of frequency between $0.01 \mathrm{~Hz}$ to $200 \mathrm{~Hz}$. A thermal regulator allows controlling the temperature inside the thermal chamber. Depending on testing temperature, adapted equipment was used to test specimen either in shear or in tension - compression modes. For temperatures higher than $20^{\circ} \mathrm{C}$, shear tests were 
performed on annular specimen with sheared height of $5 \mathrm{~mm}$, internal diameter of $8 \mathrm{~mm}$ and external diameter of $10 \mathrm{~mm}$ (Figure 1a). For temperatures lower or equal to $20^{\circ} \mathrm{C}$, tension - compression tests were performed on cylindrical specimen with height of 18 $\mathrm{mm}$ and diameter of $9 \mathrm{~mm}$ (Figure $1 \mathrm{~b}$ ). The tension - compression tests give directly the complex modulus $\mathrm{E}^{*}$ of bitumen. For the shear tests, complex modulus $\mathrm{E}^{*}$ of bitumen was calculated from measured shear complex modulus $G^{*}\left(E^{*}=3 G^{*}\right)$ by applying a Poisson's ratio equal to 0.5 .

[Figure 1 near here]
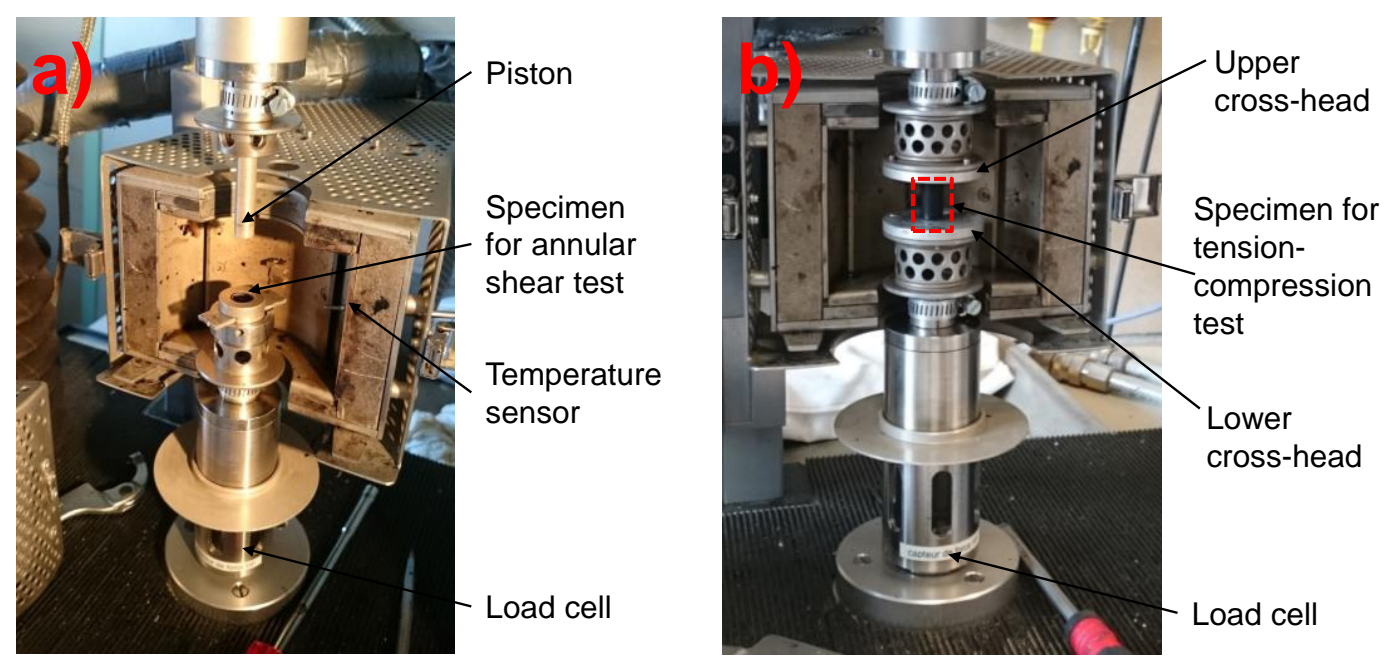

Figure 1. Metravib equipment used for testing on bitumen: a) shear test and b) tension compression test

\section{Test equipment for mixtures}

The complex modulus tests on mixtures were performed on cylindrical specimens ( 75 $\mathrm{mm}$ in diameter and $140 \mathrm{~mm}$ high) using a hydraulic press. The set up developed at University of Lyon/ENTPE laboratory allows measuring accurately the stress, the strains (axial and radial strains in the middle part of the specimen) and the temperature. The readers can find more details of this device in previous studies (Nguyen et al., 
2015a; Pham et al., 2015b).

\section{Testing}

\subsection{Tests on bitumen}

\subsubsection{Complex modulus test}

The complex modulus of bitumen was obtained by performing cyclic tests in small strain amplitude $(0.25 \%$ for shear tests, $0.014 \%$ for TC tests). Sinusoidal loading was applied on specimens at 10 temperatures (from $-20^{\circ} \mathrm{C}$ to $50^{\circ} \mathrm{C}$ ) and 7 frequencies (from $1 \mathrm{~Hz}$ to $80 \mathrm{~Hz})$.

\subsubsection{Nonlinearity test}

The nonlinearity tests were performed at 3 different temperatures $\left(10^{\circ} \mathrm{C}, 30^{\circ} \mathrm{C}, 50^{\circ} \mathrm{C}\right)$ and 4 different frequencies $(5 \mathrm{~Hz}, 10 \mathrm{~Hz}, 25 \mathrm{~Hz}, 50 \mathrm{~Hz})$. The program of nonlinearity tests is presented in Table 1. At each given temperature, three kinds of nonlinearity tests were applied on the same specimen: individual strain tests (IST), fatigue test (FT) and strain sweep tests (SST). After each kind of nonlinearity test, a 30 minutes rest period (controlled stress equal to $0 \mathrm{MPa}$ ) is maintained before performing the next kind of nonlinearity test. Detail on each type of nonlinearity test is given in Figure 2.

[Table 1 near here]

Table 1. Program of nonlinearity tests on bitumen

\begin{tabular}{|c|c|c|c|c|c|}
\hline \multirow{2}{*}{$\mathrm{T}\left({ }^{\circ} \mathrm{C}\right)$} & \multirow{2}{*}{$\begin{array}{c}\text { Type of } \\
\text { test }\end{array}$} & \multicolumn{4}{|c|}{ Frequency (Hz) } \\
\cline { 3 - 6 } & IST & $5 \mathrm{~Hz}$ & $10 \mathrm{~Hz}$ & $25 \mathrm{~Hz}$ & $50 \mathrm{~Hz}$ \\
\hline \multirow{2}{*}{$\begin{array}{c}50{ }^{\circ} \mathrm{C} \\
\text { (specimen 1) }\end{array}$} & FT & & $\checkmark$ & $\checkmark$ & $\checkmark$ \\
\hline & SST & $\checkmark$ & $\checkmark$ & $\checkmark$ & $\checkmark$ \\
\hline \multirow{2}{3}{$\begin{array}{c}30{ }^{\circ} \mathrm{C} \\
\text { (specimen 2) }\end{array}$} & IST & $\checkmark$ & $\checkmark$ & $\checkmark$ & $\checkmark$ \\
\cline { 2 - 6 } & FT & & $\checkmark$ & & \\
\cline { 2 - 6 } & SST & $\checkmark$ & $\checkmark$ & $\checkmark$ & $\checkmark$ \\
\hline
\end{tabular}




\begin{tabular}{|c|c|c|c|c|c|}
\hline \multirow{2}{*}{$10^{\circ} \mathrm{C}$} & IST & $\checkmark$ & $\checkmark$ & $\checkmark$ & $\checkmark$ \\
\hline & FT & & $\checkmark$ & & \\
\hline & SST & & $\checkmark$ & & $\checkmark$ \\
\hline
\end{tabular}

The individual strain tests (IST) consist in measuring separately the complex modulus at 4 different strain amplitudes (Figure 2a). These 4 strain amplitudes (called "strain level 1" to "strain level 4") varied with the tested temperature and are indicated in Table 2. The strain amplitude applied in tension compression mode (at $10^{\circ} \mathrm{C}$ ) is the axial strain and strain in shear mode $\left(30^{\circ} \mathrm{C}\right.$ and $\left.50^{\circ} \mathrm{C}\right)$ is the shear strain. It is underlined that the values of strain amplitude in Table 2 are targeted values. The true strain amplitude measured on the specimens during the tests can be slightly different from these targeted values. A very small number of cycles ( $\min =10$ cycles at $5 \mathrm{~Hz}$ up to $\max =75$ cycles at $50 \mathrm{~Hz}$ ) was applied at each strain amplitude in order to eliminate cyclic effects (self-heating, thixotropy and fatigue) on the measurements of complex modulus (Figure 2a). After each loading period, a stress equal to $0 \mathrm{MPa}$ (rest period) was applied on the specimen during 300s before the next loading period. Due to the special calibration system, the Metravib's DMA is able to control the strain amplitude target as soon as the first cycles. Thus, the values of complex modulus measured during each IST can be considered to be obtained from the 2 nd or $3^{\text {rd }}$ cycle, when transient effects become negligible (Gayte, Di Benedetto, Sauzéat, \& Nguyen, 2016). The fatigue tests (FT) consist in applied 10000 cycles on the sample at fixed strain amplitude. At each temperature, FT was performed with continuous cyclic loading at only one constant strain amplitude (strain level 3) and a fixed frequency of $10 \mathrm{~Hz}$ (see Table 1, Table 2, Figure 2b).

During the strain sweep tests (SST), a sweep of strain amplitude was applied on the specimen of bitumen (Figure 2c). The strain amplitude during SST increases from a 
small value up to strain amplitude level 4. As can be seen in Figure 2c, cyclic loading was applied continuously on the specimen. A loading period of IST lasts 1-2 seconds while the SST at $10 \mathrm{~Hz}$ took about 25 minutes. Hence, the cyclic effects during SST are not negligible.

[Figure 2 near here]

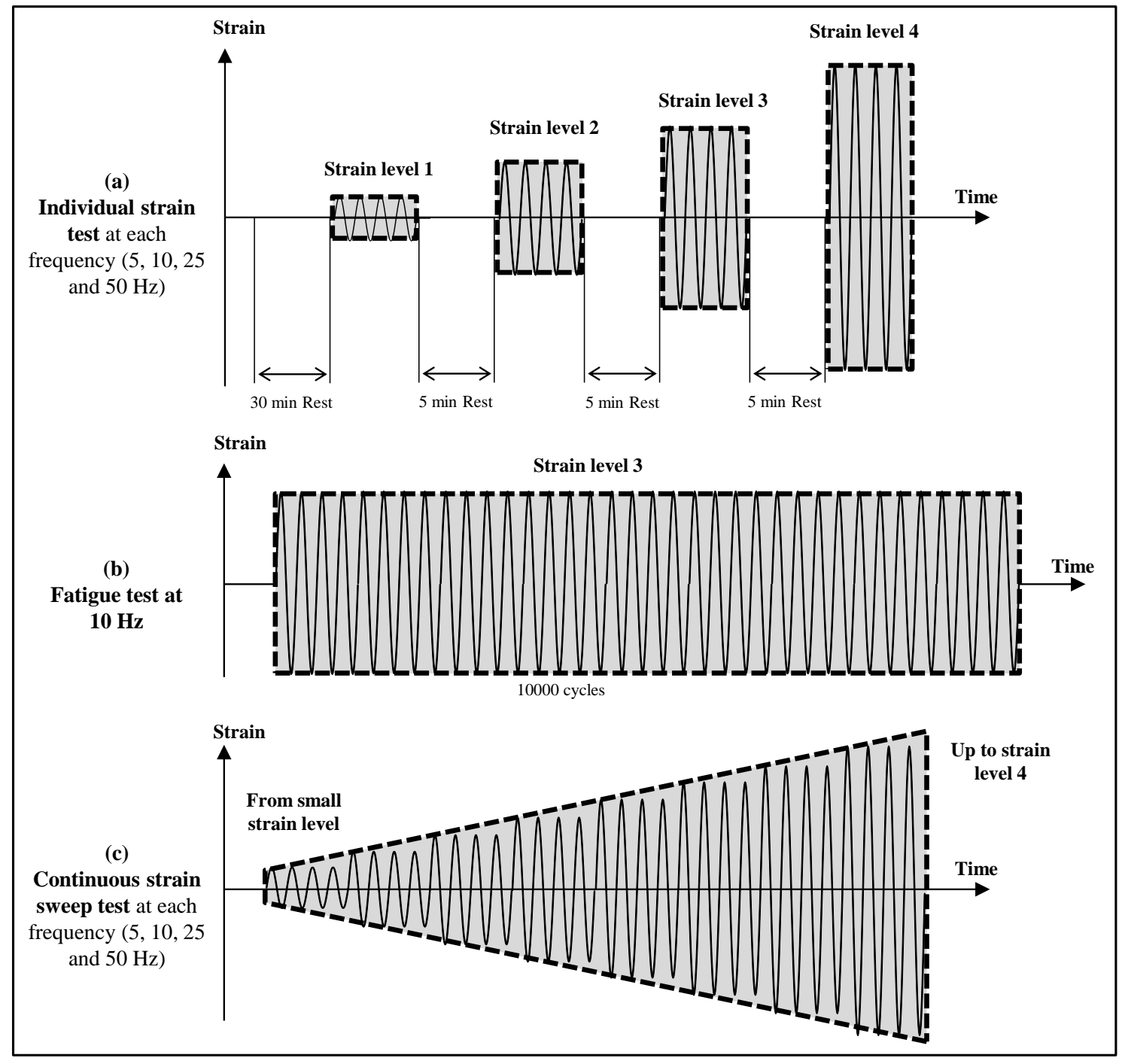

Figure 2. Testing procedure of individual strain test (IST), fatigue test (FT) and strain sweep test (SST). 
[Table 2 near here]

Table 2. Strain amplitudes applied for each kind of nonlinearity test on bitumen

\begin{tabular}{|c|c|c|c|c|c|}
\hline \multirow{2}{*}{$\mathbf{T}\left({ }^{\circ} \mathbf{C}\right)$} & \multirow{2}{*}{ Type of test } & \multicolumn{4}{|c|}{ Applied strain level } \\
\hline & & 1 & 2 & 3 & 4 \\
\hline \multirow{3}{*}{$\mathbf{5 0}^{\circ} \mathrm{C}$} & IST & $2.5 \%$ & $5 \%$ & $7.5 \%$ & $10 \%$ \\
\hline & FT & & & $7.5 \%$ & \\
\hline & SST & \multicolumn{4}{|c|}{ From small strain amplitude to strain level 4 (10\%) } \\
\hline \multirow{3}{*}{$30^{\circ} \mathrm{C}$} & IST & $1.25 \%$ & $2.5 \%$ & $3.75 \%$ & $5 \%$ \\
\hline & FT & & & $3.75 \%$ & \\
\hline & SST & \multicolumn{4}{|c|}{ From small strain amplitude to strain level $4(5 \%)$} \\
\hline \multirow{3}{*}{$10^{\circ} \mathrm{C}$} & IST & $0.075 \%$ & $0.15 \%$ & $0.225 \%$ & $0.3 \%$ \\
\hline & FT & & & $0.225 \%$ & \\
\hline & SST & \multicolumn{4}{|c|}{ From small strain amplitude to strain level $4(0.3 \%)$} \\
\hline
\end{tabular}

\subsection{Tests on bituminous mixtures}

The complex modulus of bituminous mixtures BM1 and BM2 was obtained by performing cyclic tension - compression tests. Sinusoidal loading was applied on cylindrical specimens at: 9 temperatures (from $-25^{\circ} \mathrm{C}$ to $40^{\circ} \mathrm{C}$ ), 6 frequencies (from 0.03 $\mathrm{Hz}$ to $10 \mathrm{~Hz}$ ) and 4 different axial strain amplitudes $(<100 \mu \mathrm{m} / \mathrm{m})$. A test protocol was performed to measure accurately the complex modulus. At each combination of temperature, frequency and axial strain amplitude, a small number of cycles $(\min =10$ cycles at $0.03 \mathrm{~Hz}$ up to $\max =100$ cycles at $10 \mathrm{~Hz}$ ) was applied on the specimen, that is called "a loading period". As a small number of cycles was applied, the effect of selfheating and/or cyclic effect (thixotropy, fatigue) on the change of complex modulus were negligible (Di Benedetto et al., 2011; Nguyen, Di Benedetto, \& Sauzéat, 2012; Nguyen, Di Benedetto, \& Sauzéat, 2015b). After each loading period, a stress equal to 0 $\mathrm{MPa}$ (rest period) was applied on the specimen during $300 \mathrm{~s}$ before the next loading period. Then, the self-heating and other effects of reversible phenomena, which could be considered as very small during each loading period, are not accumulated over the 
loading periods. In total, 216 values of complex modulus $\mathrm{E}^{*}$ were obtained at different temperatures, frequencies and strain amplitudes.

\section{Analysis of the results}

\subsection{Tests on bitumen}

\section{Complex modulus test on bitumen}

The master curves of norm $\left(\left|\mathrm{E}^{*}\right|\right)$ and phase angle $\left(\phi_{\mathrm{E}}\right)$ of complex modulus of bitumen are presented in Figure 3. The complex modulus data are collected from measurements at 9 different temperatures (T) and 7 different frequencies (f). Both master curves of norm and phase angle are plotted at the reference temperature $\mathrm{T}_{\mathrm{ref}}=30^{\circ} \mathrm{C}$ using the same shift factor aт. As can be seen in Figure 3, the Time Temperature Superposition Principle (TTSP) is shown to be successfully applicable to the tested bitumen. The shift factor $\mathrm{a}_{\mathrm{T}}$ and the fitting curve using the WLF law (Ferry, 1980) are presented in Figure 4.

[Figure 3 near here]

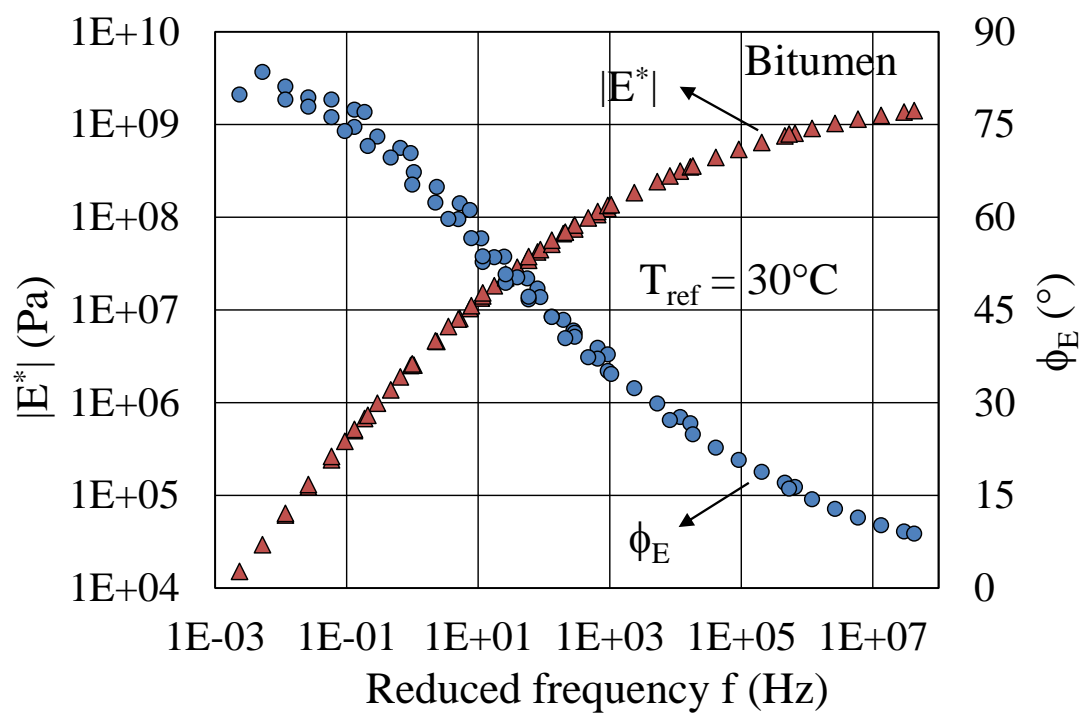

Figure 3. Master curves of norm $\left(\left|\mathrm{E}^{*}\right|\right)$ and phase angle $\left(\phi_{\mathrm{E}}\right)$ of bitumen at $\mathrm{T}_{\text {ref }}=30^{\circ} \mathrm{C}$ 
[Figure 4 near here]

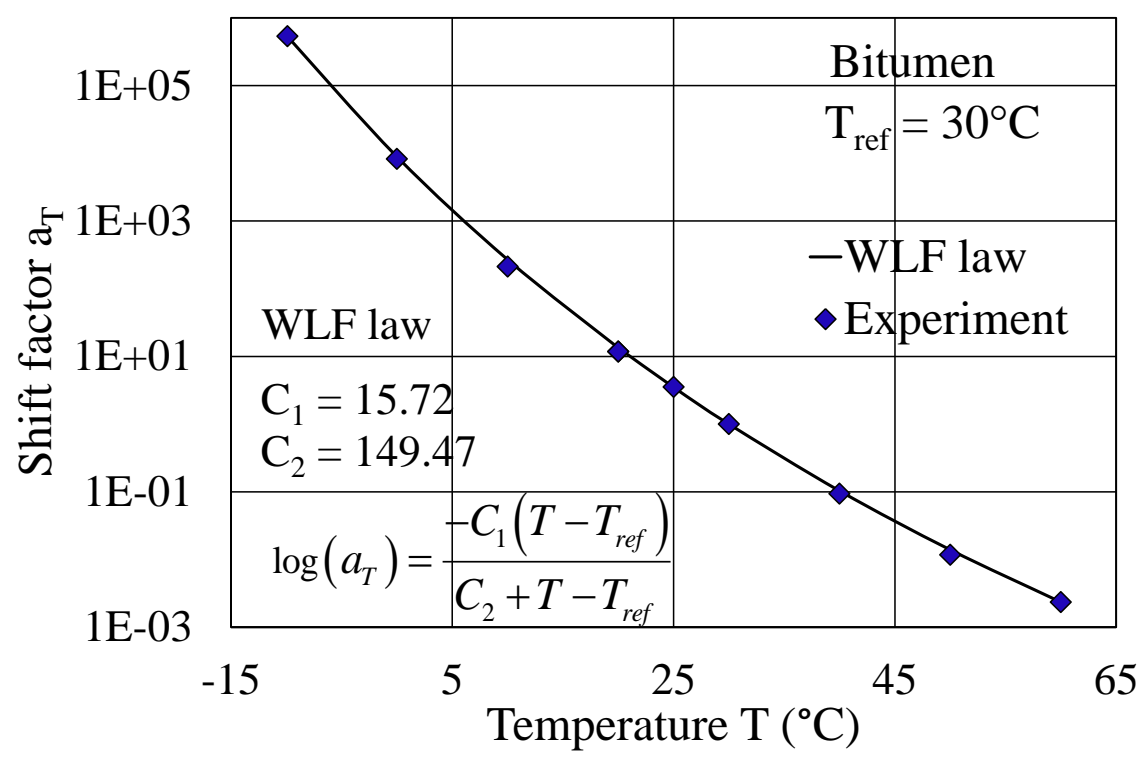

Figure 4. Shift factor $\mathrm{a}_{\mathrm{T}}$ for bitumen and fitting curve using the WLF law

\section{Nonlinearity test on bitumen}

Figure 5 and Figure 6 present the results of IST, FT, SST at $50^{\circ} \mathrm{C}$ and $10 \mathrm{~Hz}$. It should be reminded that for the temperatures higher than $20^{\circ} \mathrm{C}$, the tests were conducted in shear strain controlled mode. The norm of complex modulus (Figure 5) and the phase angle (Figure 6) are plotted as a function of the strain amplitude. As can be seen in Figure 5, the norm of complex modulus $\left|\mathrm{E}^{*}\right|$ obtained from IST decreases when the applied strain amplitude increases. This change in $\left|E^{*}\right|$ is only due to the effect of loading amplitude (nonlinearity effect) as explained previously (section 3.1.2). Meanwhile, the decrease of $\left|\mathrm{E}^{*}\right|$ during FT is also caused by cyclic effects and the one in SST can be explained by the combination of both nonlinearity and cyclic effects. The test results show a considerable difference in $\left|\mathrm{E}^{*}\right|$ obtained from IST and SST. For example, at about $7.5 \%$ of strain amplitude, the norm of complex modulus $\left|E^{*}\right|$ measured in SST is 6\% lower than the one obtained in IST that corresponds a decrease due to 1200 cycles at the same strain amplitude in FT (see Figure 5). The difference in 
$\left|E^{*}\right|$ between IST and SST becomes more significant with the increase of strain amplitude. This difference is explained by the cyclic effects (that are mainly reversible) that accumulates with the number of applied cycles in SST, while it is not the case in IST.

In case of IST, the measured $\left|E^{*}\right|$ is observed to be linear with the strain amplitude within tested range. The relationship between $\left|\mathrm{E}^{*}\right|$ and the strain amplitude is fitted by a linear regression, called "nonlinearity line" (see Figure 5). Two parameters $\left(\mathrm{m}_{\mathrm{E}}\right.$ and $\left.\left|\mathrm{E}_{0}^{*}\right|\right)$ are obtained from the nonlinearity line. $\mathrm{m}_{\mathrm{E}}$ is the slope and $\left|\mathrm{E}_{0}^{*}\right|$ is the norm of complex modulus at infinitively small amplitude (i.e., strain amplitude tends toward 0$).\left|\mathrm{E}_{0}^{*}\right|$ is considered as undamaged and "true" complex modulus of the material at a given couple of temperature and frequency. For each kind of test (IST or SST), the linear viscoelastic limit $\varepsilon_{\mathrm{LVE}}$ limit is defined as the strain amplitude corresponding to a decrease in $\left|\mathrm{E}^{*}{ }_{0}\right|$ of $5 \%$ (see Figure 5). In case of IST, $\varepsilon_{\mathrm{LVE}}$ limit is determined by interpolation or extrapolation of the measured experimental data using the nonlinearity line.

[Figure 5 near here] 


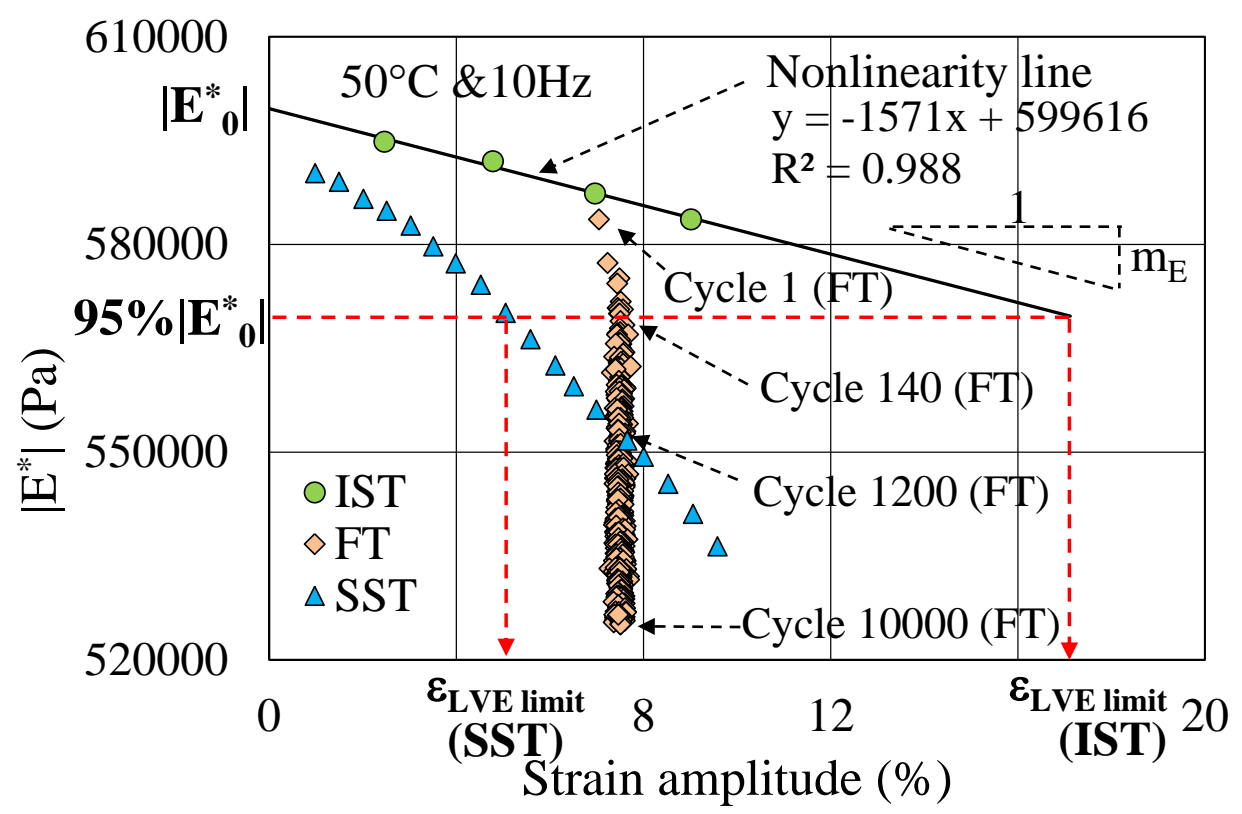

Figure 5. IST, FT, SST at $50^{\circ} \mathrm{C}$ and $10 \mathrm{~Hz}:\left|\mathrm{E}^{*}\right|$ vs. strain amplitude

As expected, the result in Figure 6 indicates that the phase angle $\phi_{\mathrm{E}}$ in IST and SST increased with the increase of the strain amplitude. The difference in $\phi_{\mathrm{E}}$ between IST and SST was clearly observed. This difference was explained previously when analysing the difference in $\left|E^{*}\right|$. The results of IST show a linear increase of $\phi_{\mathrm{E}}$ as a function of the strain amplitude within the tested range. Hence, a nonlinearity line of $\phi_{\mathrm{E}}$ could be plotted (like in the case of $\left|\mathrm{E}^{*}\right|$ ) that allowed determining two parameters: the slope of the line $m_{\phi}$ and the phase angle at $0 \%$ of strain amplitude $\phi_{\mathrm{E} 0}$. The $\phi_{\mathrm{E} \_L V E}$ limit values of IST and STT are also indicated in Figure 6. They correspond to the values obtained at strain amplitude $\varepsilon_{\text {LVE }}$ limit as defined in Figure 5.

[Figure 6 near here] 


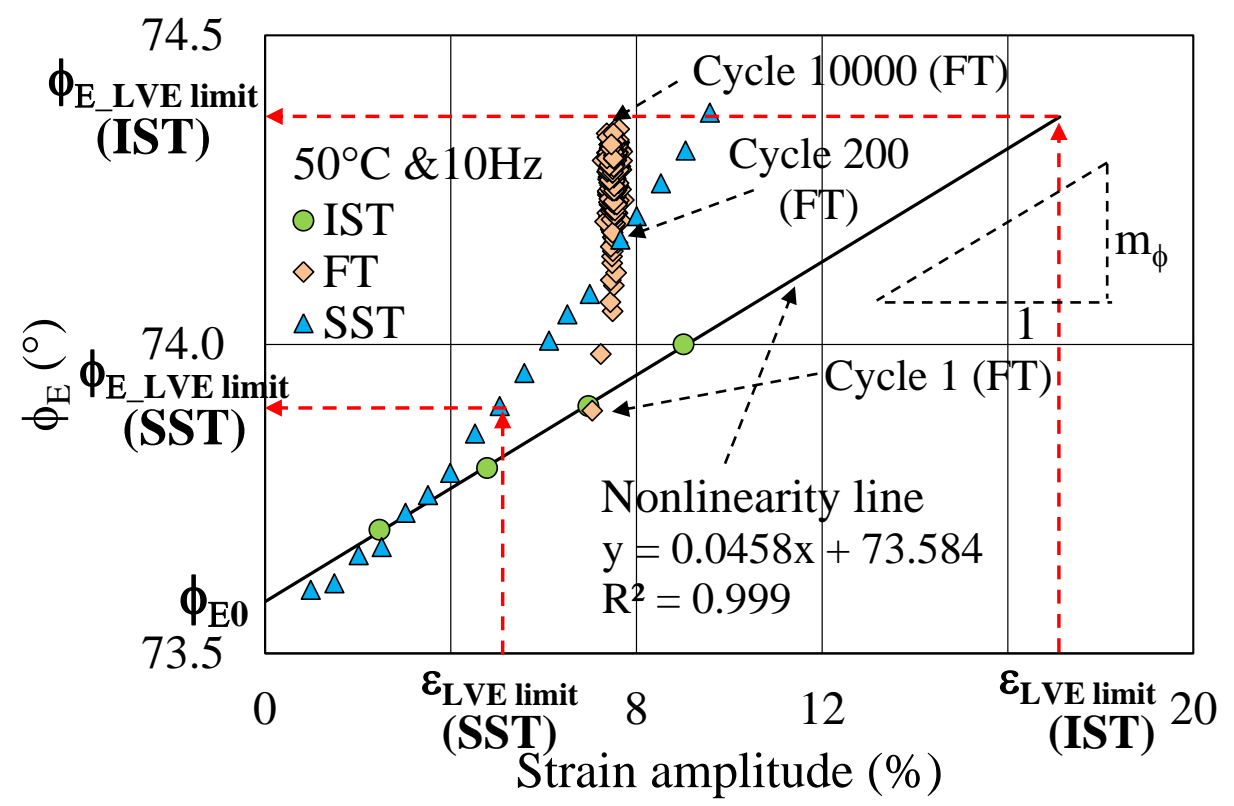

Figure 6. IST, FT, SST at $50^{\circ} \mathrm{C}$ and $10 \mathrm{~Hz}$ : $\phi_{\mathrm{E}}$ vs. strain amplitude

The results indicated that at $50^{\circ} \mathrm{C}$ and $30^{\circ} \mathrm{C}$, the nonlinearity lines which characterise the effect of strain amplitude on the complex modulus could be drawn for all frequencies and temperatures (Figure 7). This nonlinearity phenomenon is frequency and temperature dependant. Figure 8 presents the results of IST, FT and SST at $10{ }^{\circ} \mathrm{C}$. It should be reminded that tests at $10^{\circ} \mathrm{C}$ are traction-compression tests and ones at $30^{\circ} \mathrm{C}$ and $50{ }^{\circ} \mathrm{C}$ are shear tests. The decrease of complex modulus was observed for both SST at $10 \mathrm{~Hz}$ and $50 \mathrm{~Hz}$. However, due to the small amplitude applied on the specimen (max $=0.3 \%)$, the linear variation of complex modulus as a function of the strain amplitude was not observed for IST at $10^{\circ} \mathrm{C}$. We tried to do some IST where the higher strain amplitudes were applied however, that breaks the specimen quickly.

[Figure 7 near here] 


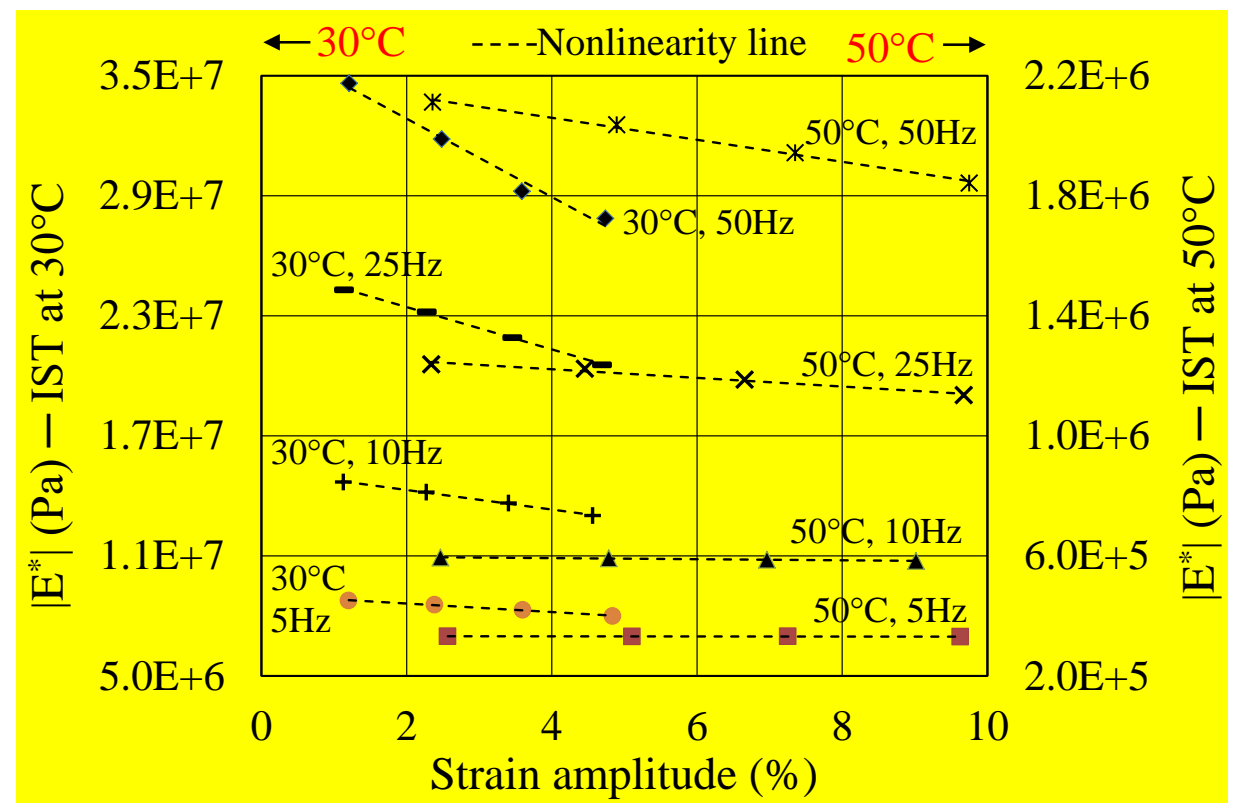

Figure 7. IST at $30^{\circ} \mathrm{C}$ and $50^{\circ} \mathrm{C}$ : $\left|\mathrm{E}^{*}\right|$ vs. strain amplitude

[Figure 8 near here]

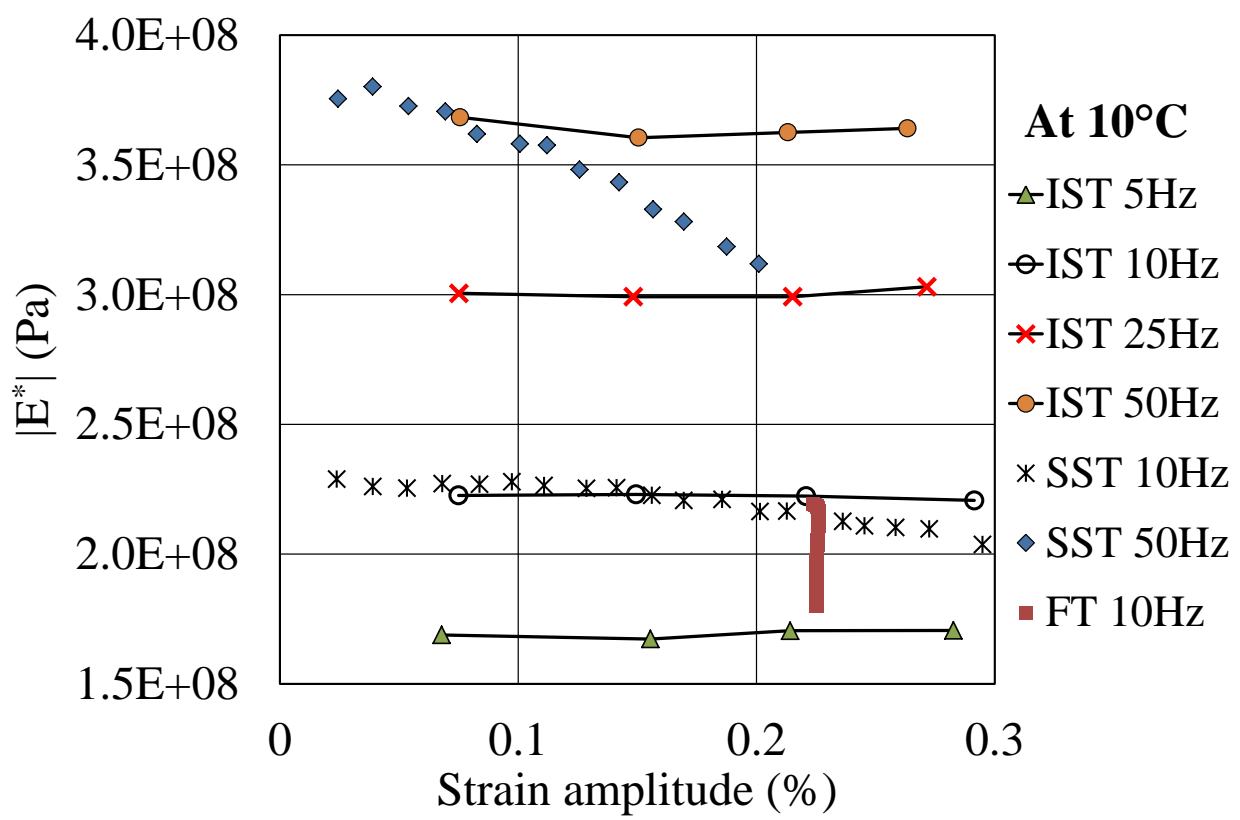

Figure 8. IST, SST and FT at $10^{\circ} \mathrm{C}:\left|\mathrm{E}^{*}\right|$ vs. strain amplitude 
Figure 9 presents the values of $\mathrm{m}_{\mathrm{E}} /\left|\mathrm{E}_{0}^{*}\right|$ and $\mathrm{m}_{\phi}$ as a function of reduced frequency. The shift factor $\mathrm{a}_{\mathrm{T}}$ used for these master curves was determined from the complex modulus test on bitumen (Figure 4). $\mathrm{m}_{\mathrm{E}} /\left|\mathrm{E}^{*}\right|$ and $\mathrm{m}_{\phi}$, the relative decrease of modulus and the absolute increase of phase angle when the strain amplitude increases by $1 \% \mathrm{~m} / \mathrm{m}$ respectively, characterise the nonlinearity effect on the complex modulus (norm and phase angle) of the bitumen. The results show that the nonlinearity effect on bitumen becomes more important at low temperature and/or high frequency and respects the TTSP.

[Figure 9 near here]

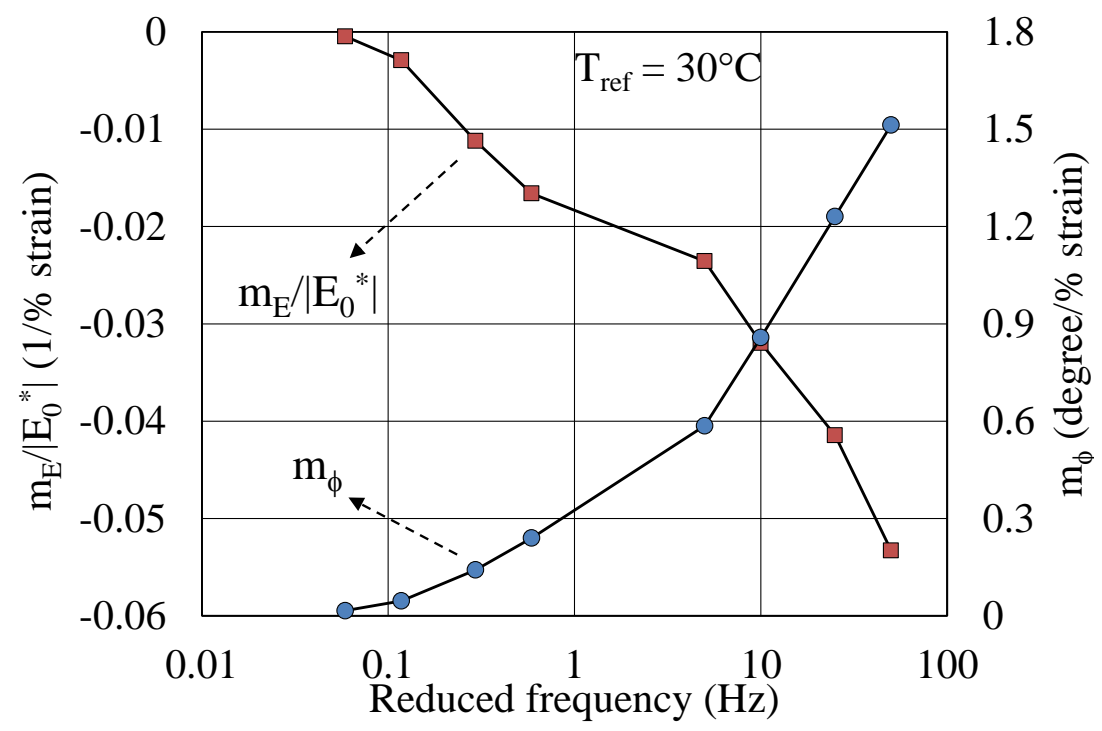

Figure $9 . \mathrm{m}_{\mathrm{E}} /\left|\mathrm{E}^{*}{ }_{0}\right|$ and $\mathrm{m}_{\phi}$ as a function of reduced frequency (bitumen 35/50)

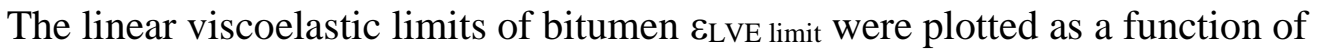

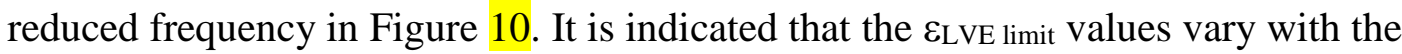
temperature/frequency couple and become higher at high temperature and/or low frequency. At $50^{\circ} \mathrm{C}$ and $5 \mathrm{~Hz}$, the linear viscoelastic limit of tested bitumen is up to 
$100 \% \mathrm{~m} / \mathrm{m}$ in IST. The $\varepsilon_{\text {LVE limit }}$ obtained from IST is clearly observed to be higher than one from SST. The difference in $\varepsilon_{\mathrm{LVE}}$ limit between IST and SST is due to the accumulated cyclic effect in SST that enhances the chute of modulus during the tests. This difference can be up to more than 10 times at high temperature/low frequency. It should be underlined that the traditional linear viscoelastic limit prescribed in references (Airey \& Rahimzadeh, 2004; SHRP-A-370) were determined using SST.

[Figure 10 near here]

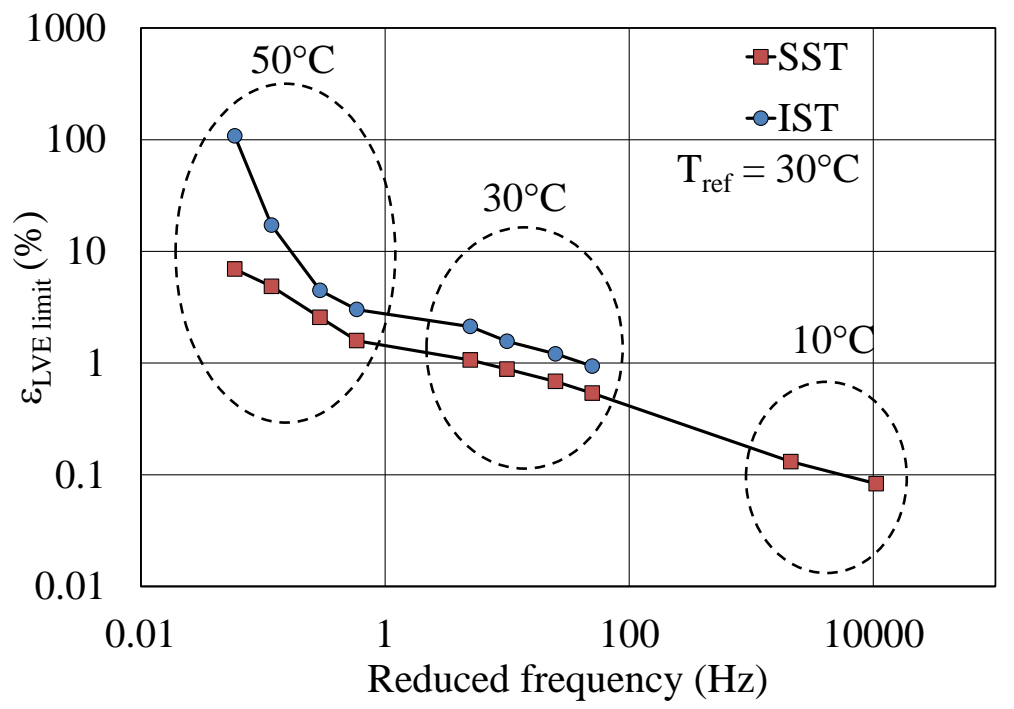

Figure 10. Linear viscoelastic limits $\varepsilon_{\mathrm{LVE}}$ limit of bitumen vs. reduced frequency

Figure 11 presents the change in phase angle, $\left(\phi \phi_{\mathrm{E}} \mathrm{LVE}\right.$ limit $\left.-\phi \mathrm{E} 0\right)$, when the strain

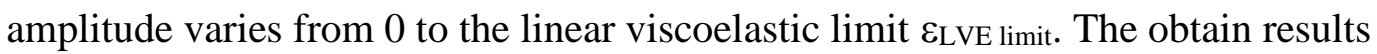
indicated that this increase of phase angle ranged between 0 and 2 degrees for all tested temperatures and frequencies.

[Figure 11 near here] 


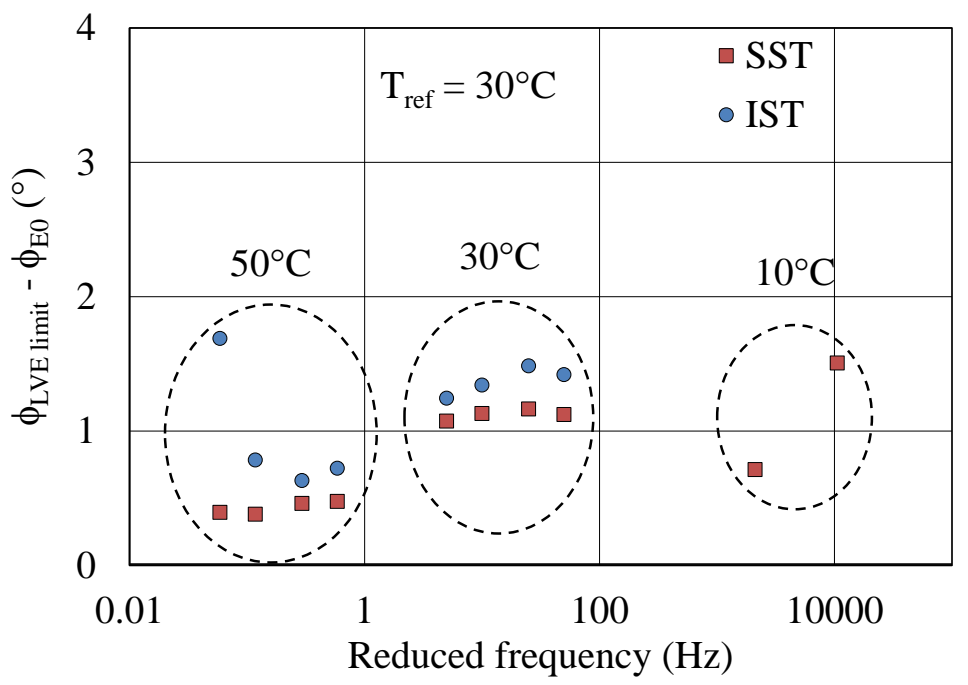

Figure 11. ( $\left.\phi_{\mathrm{E} \_L V E \text { limit }}-\phi_{\mathrm{E} 0}\right)$ vs. reduced frequency (bitumen 35/50)

\subsection{Tests on bituminous mixtures}

Nguyen et al. (2015a) have been performed the complex modulus tests at different levels of strain amplitude on a bituminous mixture using PG64-22 binder and analysed carefully the 3 dimensional (3D) nonlinear viscoelastic behaviour of the mixture. In this section, only main results that allow observing how the nonlinear behaviour changes from binder to mixes, are presented. For detailed analysis of nonlinearity phenomenon on mixtures such as : nonlinearity of complex Poisson's ratio, nonlinearity effects in Black space and modelling, readers are invited to consult paper by Nguyen et al. (2015a).

The evolution of $\mathrm{E}^{*}$ (both norm and phase angle) as a function of strain amplitude was illustrated in Figure 12 and Figure 13. The plotted data was collected from measurements at $16.2{ }^{\circ} \mathrm{C}$ and at 6 different frequencies. When increasing the strain amplitude, the decrease of modulus and the increase of phase angle were observed. The change in complex modulus was indicated to be linear with the strain amplitude. This observation is valid for all other tested temperatures. In the same way as bitumen 
(Figure 5), the nonlinearity lines can be drawn and the parameters $\left(\left|\mathrm{E}_{0}^{*}\right|, \mathrm{m}_{\mathrm{E}}, \varepsilon_{\mathrm{LVE}}\right.$ limit, $\phi_{\mathrm{E} 0}$ and $\left.\mathrm{m}_{\phi}\right)$ can be determined for bituminous mixtures BM1 and BM2.

[Figure 12 near here]

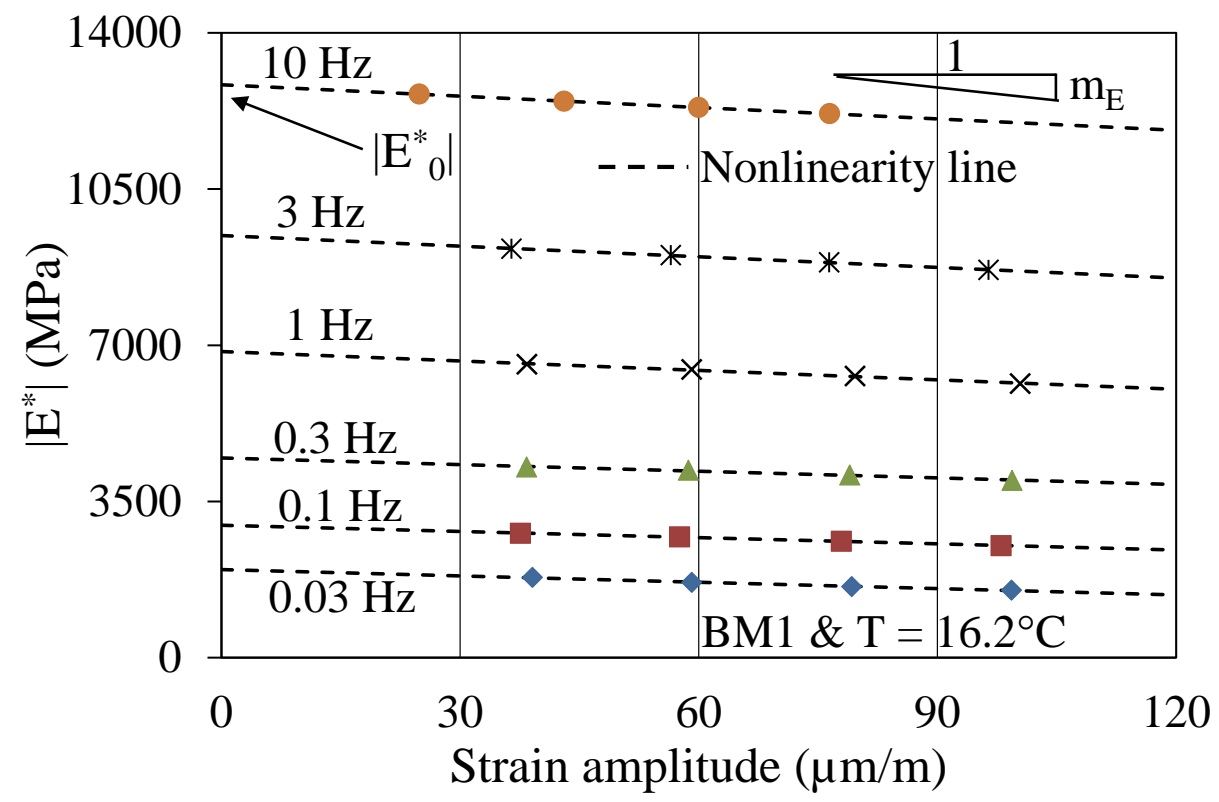

Figure 12. Results at $16.2{ }^{\circ} \mathrm{C}$ for bituminous mixture (BM1), $\left|\mathrm{E}^{*}\right|$ versus Strain amplitude

[Figure 13 near here] 


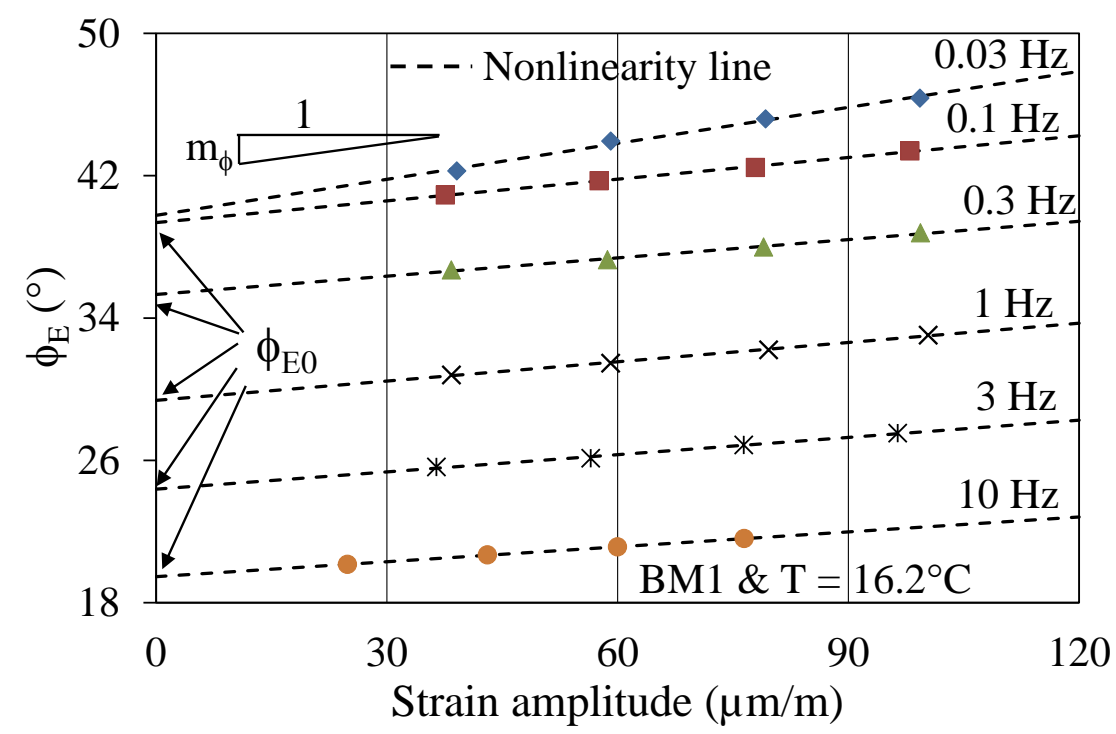

Figure 13. Results at $16.2{ }^{\circ} \mathrm{C}$ for bituminous mixture (BM1), $\phi_{\mathrm{E}}$ versus strain amplitude The master curves of the "true" complex modulus $\mathrm{E}^{*}{ }_{0}$ (norm $\left|\mathrm{E}^{*}{ }_{0}\right|$ and phase angle $\phi_{\mathrm{E} 0}$ obtained when strain amplitude teds toward 0) of BM1 and BM2 are presented in Figure 14. A small difference in complex modulus between BM1 and BM2 was observed at very high and very low reduced frequencies. The obtained results indicate that the bituminous mixtures respect the TTSP. The values of shift factor aт used to plot the master curves of mixtures and bitumen are plotted in Figure 15. The identical shift factors obtained for mixtures and bitumen indicated that this parameter is fixed by the bitumen and that the aggregate grading has negligible influence on this parameter. This noticeable result was also verified by some other researches (Di Benedetto et al., 2004; Olard, Di Benedetto, Dony, \& Vaniscote, 2005; Nguyen, Di Benedetto, \& Sauzéat, 2013).

[Figure 14 near here] 


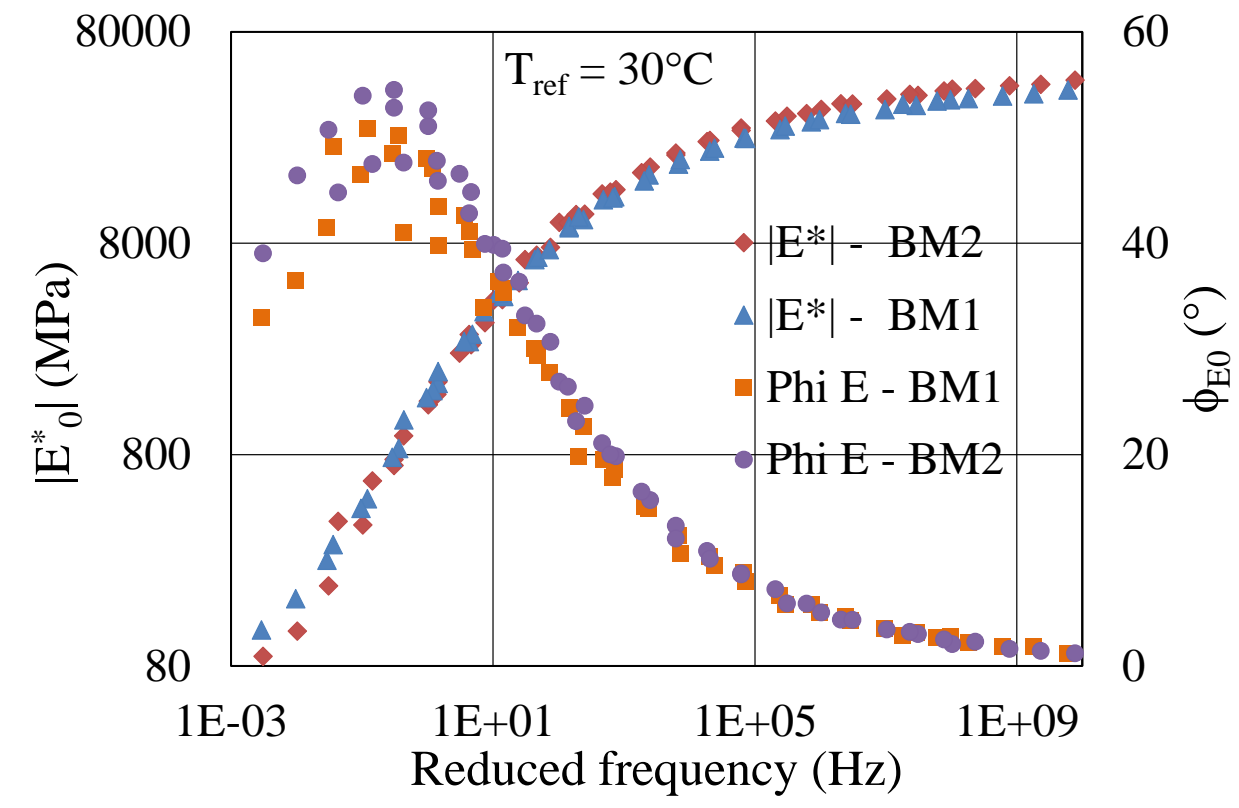

Figure 14. $\mathrm{E}^{*}{ }_{0}$ master curves of bituminous mixtures BM1 and BM2

[Figure 15 near here]

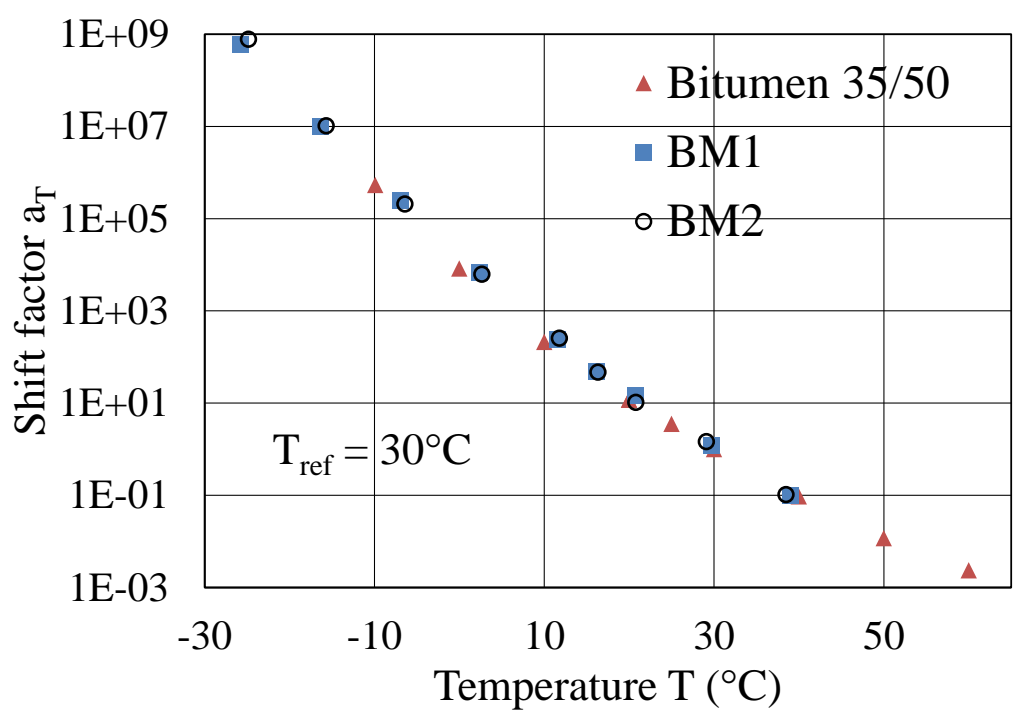

Figure 15. Shift factors $\mathrm{a}_{\mathrm{T}}$ for mixtures and bitumen

The two parameters $m_{E} /\left|E_{0}^{*}\right|$ and $m_{\phi}$, which are considered to characterise the nonlinearity effect on the complex modulus of the bituminous mixture, were plotted in Figure 16. The shift factors a obtained in the linear domain (Figure 15) were used to 
plot the master curves of $\mathrm{m}_{\mathrm{E}} /\left|\mathrm{E}^{*}{ }_{0}\right|$ and $\mathrm{m}_{\phi}$. It can be seen on Figure 16 that these nonlinearity parameters respect the TTSP and then, depend on temperature-frequency couples. When comparing with the nonlinearity phenomenon on bitumen (Figure 9), it is interesting and surprising to notice that the evolution of the 2 parameters with reduced frequency is opposite between mixtures and bitumen. The nonlinearity effect on bituminous mixtures becomes more significant at high temperatures and/or low frequencies. At very high temperature (low frequency), the value $\mathrm{m}_{\mathrm{E}} /\left|\mathrm{E}_{0}^{*}\right|$ of mixture is about $-0.005(1 / \mu$ strain) that can be compared with the one of unbound materials ( $\mathrm{Di}$ Benedetto, Tatsuoka, Geoffroy, \& Lo Presti, 2015)

[Figure 16 near here]

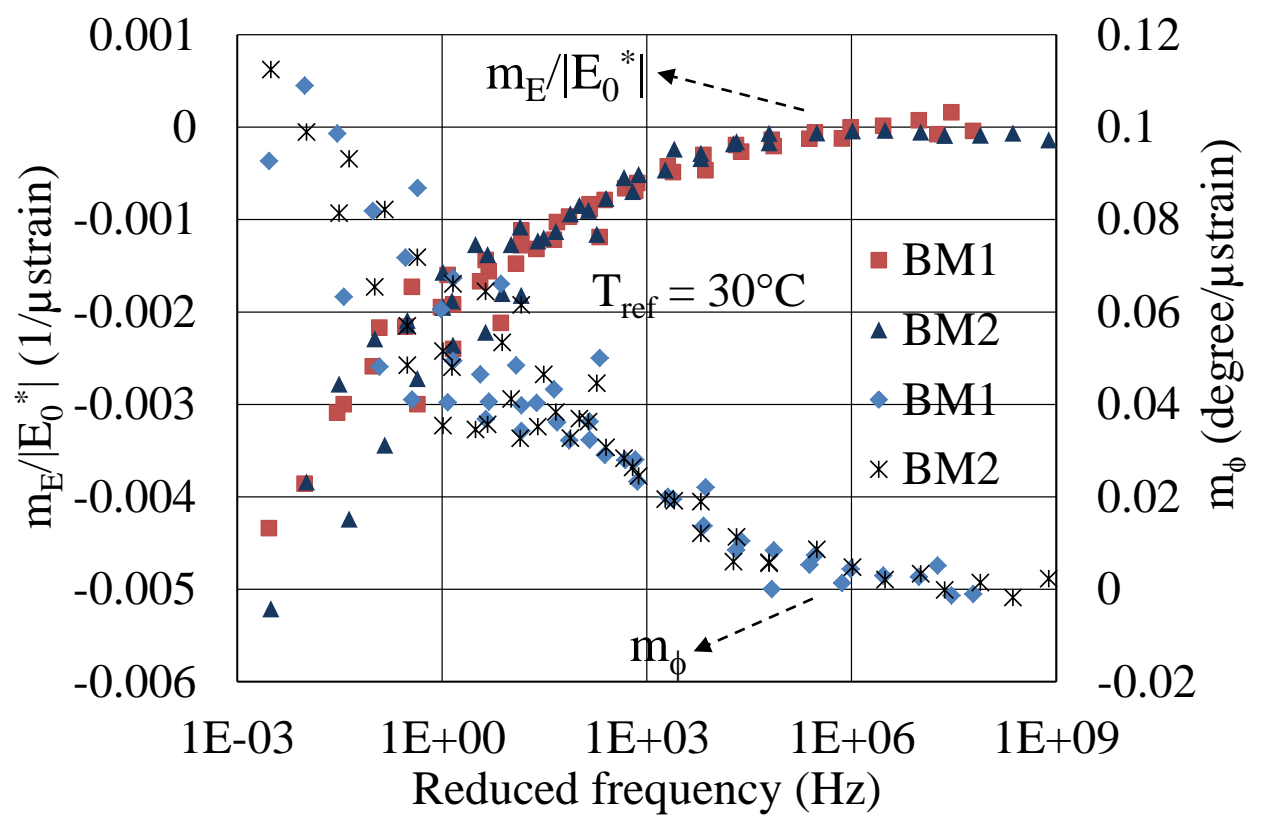

Figure 16. $\mathrm{m}_{\mathrm{E}} /\left|\mathrm{E}_{0}^{*}\right|$ and $\mathrm{m}_{\phi}$ as a function of reduced frequency (bituminous mixtures $\mathrm{BM} 1$ and BM2) at reference temperature of $30^{\circ} \mathrm{C}$

The values of $\varepsilon_{\mathrm{LVE}}$ limit and the change in phase angle ( $\phi_{\mathrm{E} \_L V E}$ limit $\left.-\phi E 0\right)$ of mixtures were plotted as a function of reduced frequency in Figure 17. The $\varepsilon_{\text {LVE limit }}$ of 
mixtures varied from $10 \mu$ strain $(0.001 \%)$ at very low frequency to $1200 \mu$ strain $(0.12 \%)$ at very high frequency. It is reminded that $100 \mu$ strain is considered as the traditional linear viscoelastic limit of mixtures in literature. The increase in $\varepsilon_{\mathrm{LVE}}$ limit of mixtures with the increase of reduced frequency is in opposite direction when comparing with the one of bitumen (Figure 10). At low frequency and/or high temperature, the difference in $\varepsilon_{\mathrm{LVE}}$ limit between bitumen and mixture can be up to 100 000 times. The change in phase angle $\left(\phi_{\mathrm{E} \_\mathrm{LVE}}\right.$ limit $\left.-\phi \mathrm{E} 0\right)$ of mixtures is rather constant and small (about $2^{\circ}$ in average value) as it is the case of bitumen.

[Figure 17 near here]

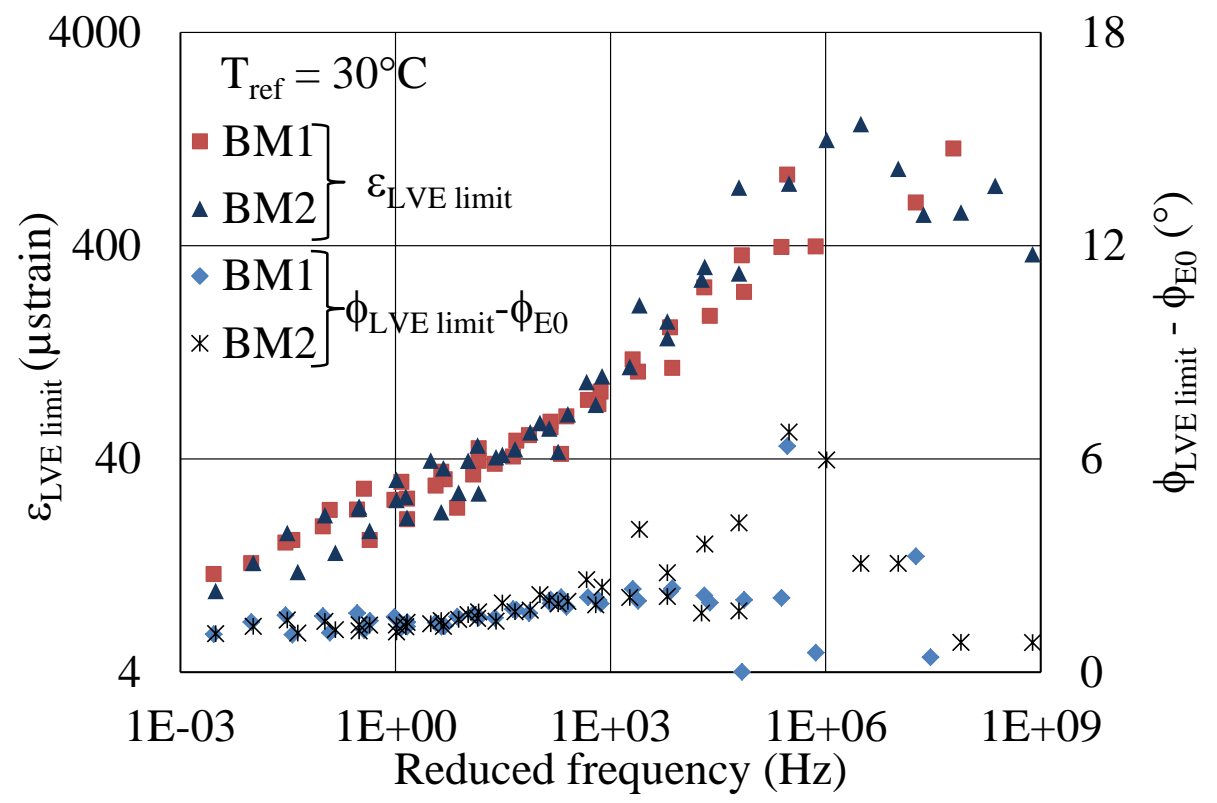

Figure 17. $\varepsilon_{\mathrm{LVE}}$ limit and ( $\phi_{\mathrm{E} \_\mathrm{LVE}}$ limit - $\left.\phi_{\mathrm{E} 0}\right)$ vs. reduced frequency (bituminous mixtures $\mathrm{BM} 1$ and BM2) at reference temperature of $30^{\circ} \mathrm{C}$ 
The $m_{\phi}$ values were plotted as a function of $m_{E} /\left|E_{0}^{*}\right|$ values in Figure 18 for the considered bitumen and two mixtures. For the visibility, $\mathrm{m}_{\mathrm{E}} / \mathrm{E}^{*}{ }_{0} \mid$ and $\mathrm{m}_{\phi}$ values of mixtures in Figure 18 were scaled to be 10 times greater than one presented in Figure 16. The results indicated a linear relationship between $\mathrm{m}_{\mathrm{E}} /\left|\mathrm{E}_{0}^{*}\right|$ and $\mathrm{m}_{\phi}$ values for both bitumen and mixtures. The linear fitting lines for the bitumen and the two mixtures BM1, BM2 were nearly identical. The angle $\lambda$ (Figure 18) represents the direction of complex modulus decrease in the Back and Cole-Cole diagram (Nguyen et al., 2015a). The same angle $\lambda$ obtained for bitumen and mixtures implied that when the strain amplitude increases, the complex modulus of bitumen and mixtures move in the same direction in the Back and Cole-Cole diagram. This remark should be taken into account when modelling the nonlinearity phenomenon from binder to mixtures.

[Figure 18 near here]

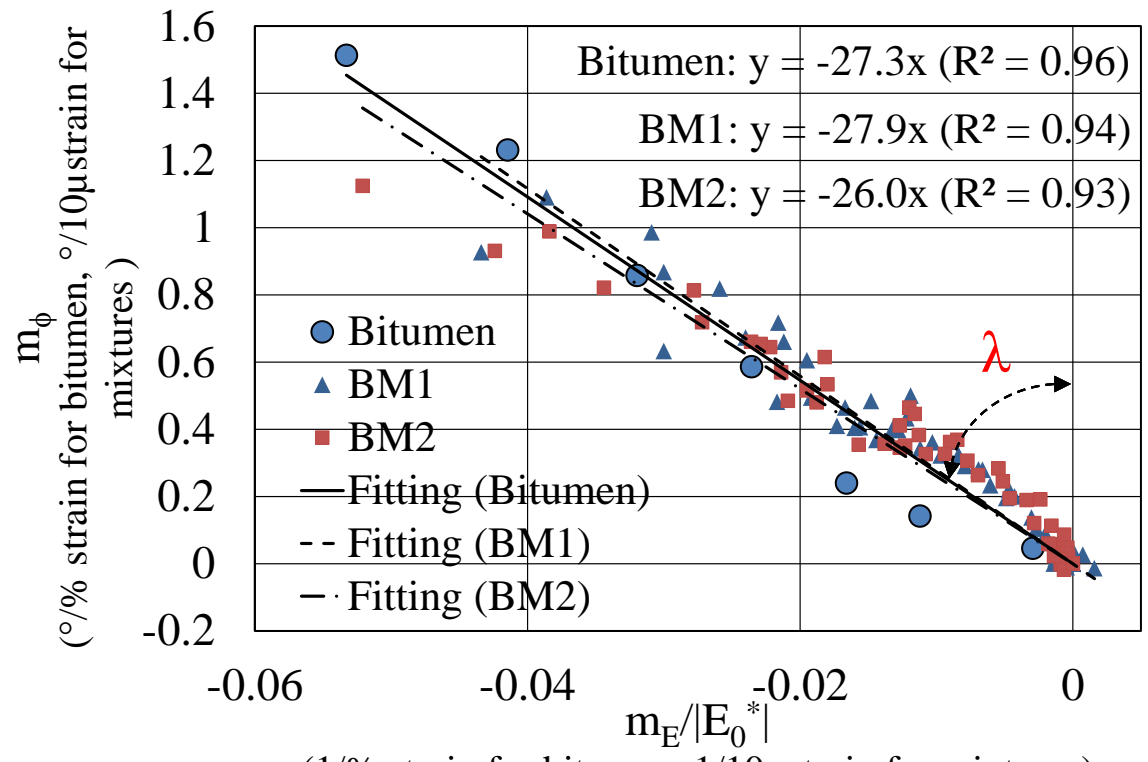

( $1 / \%$ strain for bitumen, $1 / 10 \mu$ strain for mixtures)

Figure 18. $\mathrm{m}_{\phi}$ as a function of $\mathrm{m}_{\mathrm{E}} /\left|\mathrm{E}^{*}{ }_{0}\right|$ scales are in a ratio of 100 between bitumen and mixtures 


\section{Conclusions}

This paper investigates on the nonlinear behaviour of bitumen and mixtures. Only rather small strain amplitudes (lower than $100 \mu \mathrm{m} / \mathrm{m}$ for mixtures and $10 \%$ for bitumen) were considered. From analysis of obtained results, the following conclusions can be drawn:

- The nonlinearity effect (effect of loading amplitude) on both bitumen and bituminous mixtures depend on temperature-frequency couple and respect the TTSP.

- The same shift factors can be considered to plot the master curves of $m_{E} /\left|E_{0}^{*}\right|$ and $m_{\phi}$ (two parameters characterising the nonlinearity phenomenon) of both bitumen and mixtures. These shift factors are also used to plot the master curves of $\mathrm{E}^{*}$ that characterise the viscoelastic behaviour of bituminous materials.

- A change in temperature - frequency couple value has inverse effects on the nonlinear behaviour of bitumen and bituminous mixtures. The nonlinear effect becomes more significant at low temperature/high frequency for bitumen while it is at high temperature/low frequency for mixtures. The $\varepsilon_{\mathrm{LVE}}$ limit of bituminous mixtures can attain $1200 \mu \mathrm{m} / \mathrm{m}$ at low temperature/high frequency, which is about 10 times greater than the classically considered linear viscoelastic limit $(100 \mu \mathrm{m} / \mathrm{m})$.

- The cyclic effect on bitumen was shown to be not negligible when comparing the results of IST and SST. The difference in $\varepsilon_{\mathrm{LVE}}$ limit between IST and the classical nonlinear test SST can be up to more than 10 times at $50^{\circ} \mathrm{C}$ and $5 \mathrm{~Hz}$.

- The change in phase angle $\left(\phi_{E_{-} L V E}\right.$ limit $\left.-\phi_{\mathrm{E} 0}\right)$ (when the strain amplitude varies from 0 to the linear viscoelastic limit $\varepsilon_{\mathrm{LVE}}$ limit) of bitumen and mixtures is small (average value of $2^{\circ}$ for mixtures and lower than $2^{\circ}$ for bitumen) and rather constant in the whole tested temperature and frequency. 
- The decrease of complex modulus on bitumen and mixtures moves on the same directions in Black and Cole-Cole diagram. This result could help to model the nonlinearity phenomenon from binder to mixtures.

\section{Funding}

This work was funded by Vietnam National Foundation for Science and Technology

Development (NAFOSTED) under Grant number 107.02-2014.22.

\section{Disclosure statement}

No potential conflict of interest was reported by the authors.

\section{References}

Airey, G. D., \& Rahimzadeh, B. (2004). Combined bituminous binder and mixture linear rheological properties. Construction and Building Materials, 18, 535-548.

Airey, G., Rahimzadeh, B., \& Collop, A. (2003). Viscoelastic linearity limits for bituminous materials. 6th International RILEM Symposium on Performance Testing and Evaluation of Bituminous Materials, 331-338.

Baaj, H., Ech, M., Tapsoba, N., Sauzéat, C., \& Di Benedetto, H. (2013).

Thermomechanical characterization of asphalt mixtures modified with high contents of asphalt shingle modifier (ASM $®$ ) and reclaimed asphalt pavement (RAP). Materials and Structures, 46 (10), 1747-1763. doi: 10.1617/s11527013-0015

Babadopulos, L., Sauzéat, C., \& Di Benedetto, H. (2017). Softening and Local Selfheating of Bituminous Mixtures During Cyclic Loading. Road Materials and Pavement Design, 18 (2), 164-177. doi:10.1080/14680629.2017.1304260.

Chehab, G. R., Kim, Y. R., Schapery, R. A., Witczak, M. W., \& Bonaquist, R. (2002). Time-Temperature superposition principle for asphalt concrete mixtures with growing damage in tension state. Asphalt Paving Technology, 71, 559-593. 
Delaporte, B., Di Benedetto, H., Chaverot, P., \& Gauthier, G. (2009). Linear viscoelastic properties of bituminous materials including new products made with ultrafine particles. Road Materials and Pavement Design, 10(1), 7-38.

Di Benedetto, H., Delaporte, B., \& Sauzéat, C. (2007). Three-dimensional linear behavior of bituminous materials: experiments and modeling. International Journal of Geomechanics, 7 (2), 149-157.

Di Benedetto, H., Nguyen, Q. T., \& Sauzéat, C. (2011). Nonlinearity, Heating, Fatigue and Thixotropy during Cyclic Loading of Asphalt Mixtures. Road Materials and Pavement Design, 12 (1), 129-158.

Di Benedetto, H., Olard, F., Sauzéat, C., \& Delaporte, B. (2004). Linear viscoelastic behavior of bituminous materials: from binders to mixes. Road Materials and Pavement Design, Vol.5, Special Issue, 163-202.

Di Benedetto, H., Sauzéat, C., \& Sohm, J. (2009). Stiffness of bituminous mixtures using ultrasonic waves propagation. Road Materials and Pavement Design, 10 (4), 789-814.

Di Benedetto, H., Tatsuoka, F., Geoffroy, H., \& Lo Presti, D. (2005). Time effects on the behaviour of geomaterials, In Deformation Characteristics of Geomaterials: recent investigations and prospects. Balkema Publishers, 59-124.

Ferry, J. D. (1980). Viscoelastic Properties of Polymers. John Wiley \& Sons.

Gauthier, G., Bodin, D., Chailleux, E., \& Gallet T. (2010). Non Linearity in Bituminous Materials during Cyclic Tests. Road Materials and Pavement Design, 11 (1), $379-410$.

Gayte, P., Di Benedetto, H., Sauzéat, C., \& Nguyen, Q. T. (2016). Influence of transient effects for analysis of complex modulus tests on bituminous mixtures. Road Materials and Pavement Design, 17 (2), 271-289. doi:10.1080/14680629.2015.1067246

Mangiafico, S., Babadopulos, L. F. A. L., Sauzéat, C., \& Di Benedetto, H. (2017) Nonlinearity of bituminous mixtures. Mechanics of Time Dependent Materials, https://doi.org/10.1007/s11043-017-9350-3.

Mangiafico, S., Di Benedetto, H., Sauzéat, C., Olard, F., Pouget, S., \& Planque, L. (2013). Influence of reclaimed asphalt pavement content on complex modulus of asphalt binder blends and corresponding mixes: experimental results and modelling. Road Materials and Pavement Design, 14, SI, 132-148. 
Mangiafico, S., Sauzéat, C., Di Benedetto, H., Pouget, S., Olard, F., \& Planque L. (2015). Quantification of biasing effects during fatigue tests on asphalt mixes: non-linearity, self-heating and thixotropy. Road Materials and Pavement Design, 16, SI 2 AAPT, 74-99. doi:10.1080/14680629.2015.1077000

Nguyen, M. L., Sauzéat, C., Di Benedetto, H., \& Tapsoba, N. (2013). Validation of the Time-Temperature superposition principle for crack propagation in bituminous mixtures. Materials and Structures, 46 (7), 1075-1087. doi: 10.1617/s11527012-9954-7

Nguyen, Q. T., Di Benedetto, H., \& Sauzéat, C. (2012). Determination of Thermal Properties of Asphalt Mixtures as Another Output from Cyclic TensionCompression Test. Road Materials and Pavement Design, 13 (1), 85-103. Nguyen, Q. T., Di Benedetto, H., \& Sauzéat, C. (2013). Prediction of linear viscoelastic behaviour of asphalt mixes from binder properties and reversal. International RILEM Symposium on Multi-Scale Modeling and Characterization of Infrastructure Materials, Stockholm, Sweden, 237-248.

Nguyen, Q. T., Di Benedetto, H., \& Sauzéat, C. (2015a). Linear and nonlinear viscoelastic behaviour of bituminous mixtures. Materials and Structures, 48 (7), 2339-2351. doi: 10.1617/s11527-014-0316-5

Nguyen, Q. T., Di Benedetto, H., \& Sauzéat, C. (2015b). Effect of fatigue cyclic loading on linear viscoelastic properties of bituminous mixtures. Journal of Materials in Civil Engineering, 27 (8). doi:10.1061/(ASCE)MT.19435533.0000996.

Nguyen, Q. T., Di Benedetto, H., Sauzéat, C., \& Tapsoba, N. (2013) Time Temperature Superposition Principle Validation for Bituminous Mixes in the Linear and Nonlinear Domains. Journal of Materials in Civil Engineering, 25 (9), 11811188.

Nguyen, Q.T., Di Benedetto, H., Sauzéat, C., Nguyen, M. L., \& Hoang, T. T. N. (2017). 3D complex modulus tests on bituminous mixture with sinusoidal loadings in tension and/or compression, Materials and Structures, 50: 98. doi:10.1617/s11527-016-0970-x.

Olard, F., Di Benedetto, H. , Dony, A., \& Vaniscote, J. C. (2005). Properties of bituminous mixtures at low temperatures and relations with binder characteristics. Materials and structures, 38 (1), 121-126. 
Perraton, D., Di Benedetto, H., Sauzéat, C., Hofko, B., Graziani, A., Nguyen, Q. T., Pouget, S., Poulikakos, L. D., Tapsoba, N., \& Grenfell, J. (2016). 3Dim experimental investigation of linear viscoelastic properties of bituminous mixtures. Materials and structures, 49 (11), 4813-4829. doi: 10.1617/s11527016-0827-3

Pham, N. H., Sauzéat, C., Di Benedetto, H., Gonzalez-Leon, J. A., Barreto, G., Nicolai, A., \& Jakubowski, M. (2015a). Analysis and modeling of 3D complex modulus tests on hot and warm bituminous mixtures. Mechanics of Time Dependent Materials, 19 (2), 167-186. doi:10.1007/s11043-015-9258-8

Pham, N. H., Sauzéat, C., Di Benedetto, H., Gonzalez-Leon, J. A., Barreto, G., Nicolai, A., \& Jakubowski, M. (2015b). Reclaimed Asphalt Pavement and additives influence on 3D linear behaviour of warm mix asphalts. Road Materials and Pavement Design, 16 (3), 569-591. doi:10.1080/14680629.2015.1021108

Schwartz, C. W., Gibson, N., \& Schapery, R. A. (2002). Time-temperature superposition for asphalt concrete at large compressive strains. Transportation Research Record, 1789, 101-112.

SHRP-A-370. (1994). Binder Characterization and Evaluation. Volume 4: Test Methods Tapsoba, N., Sauzéat, C., \& Di Benedetto, H. (2013). Analysis of fatigue test for bituminous mixtures. Journal of Materials in Civil Engineering, 25 (6), 701710. doi:10.1061/(ASCE)MT.1943-5533.0000636

Underwood, B. S., \& Kim, Y. R. (2015). Nonlinear viscoelastic analysis of asphalt cement and asphalt mastics. International Journal of Pavement Engineering, 16(6), 510-529. DOI: 10.1080/10298436.2014.943133

Zhao, Y., \& Kim, Y. R. (2003). Time-temperature superposition for asphalt mixtures with growing damage and permanent deformation in compression. Transportation Research Record, 1832, 161-172. 